\title{
Effets de la vitesse de croissance au pâturage chez des taurillons finis en stabulation : I. Performances zootechniques
}

\author{
I Dufrasne, JL Hornick, S Gauthier, N Korsak, L Istasse \\ Service de Nutrition, Fac Méd Vét, Univ de Liège, Sart-Tilman, 43-4000 Liège, Belgique
}

En Belgique, l'engraissement à l'étable de taurillons culards peut-être précédé d'une période de pâturage avant la période de finition en stabulation. Les répercussions de deux modalités de pâturage sur la vitesse de croissance et sur les caractéristiques de la carcasse ont été étudiées chez des taurillons Blanc Bleu belge finis en stabulation.

Vingt taurillons pesant $250 \mathrm{~kg}$ en moyenne ont été répartis en un groupe de 4 animaux témoins $(T)$, engraissés en stabulation et deux groupes de 8 animaux ayant pâturé pendant 140 jours dans un système de pâturage continu intensif. Le chargement de pâturage a été soit modéré de manière à réaliser une croissance classique en prairie (CCP), soit élevé afin de limiter la croissance de animaux (CFP). Le groupe CCP a disposé de 1,33 ha dont un tiers a été réservée pour la fauche. Le chargement moyen a été de 6 taurillons par ha et $121 \mathrm{~kg} \mathrm{~N} /$ ha ont été apportés en trois fois. La superficie allouée à l'autre groupe était de 0,80 ha et le chargement de 10 taurillons par ha. L'apport de fumure azotée a été de $111 \mathrm{~kg}$ $\mathrm{N} /$ ha. Cent mesures de hauteur d'herbe ont été réalisées tous les 14 jours à l'aide d'un herbomètre à plateau. Le pourcentage de refus a été estimé à la fin de la saison de pâturage sur 11 bandes de 50 mètres par ha. Les animaux ont été pesés tous les 28 jours.
Rentrés en stabulation, ils ont reçu un aliment concentré d'engraissement à base de pulpes séchées et ont été abattus en fonction de leur état d'engraissement, qui a été estimé par maniement sous-cutané de la base de la queue, du pli du grasset et des côtes. Les carcasses ont été pesées et les côtes 7,8 et 9 ont été prélevées deux jours après l'abattage et disséquées afin de déterminer la composition de la carcasse.

Les hauteurs d'herbe ont été de $7,03 \mathrm{~cm}$ et de $5,21 \mathrm{~cm}$ dans les groupes CCP et CFP (SED $0,88, P<0.05)$ ce qui prouve que les animaux du lot CFP ont pâturé plus ras afin d'adapter leur ingestion d'herbe. Les valeurs correspondantes pour les pourcentages de refus ont été de 5,52 et de $2,96 \%$. Ces résultats indiquent que le pâturage a été très intensif dans le cas des animaux CFP. Les taurillons qui avaient effectué une croissance faible en prairie ont réalisé une croissance compensatrice et ont amélioré leur efficacité alimentaire pendant la période de finition. Pour une durée d'engraissement semblable dans tous les lots, les gains ont été plus élevés dans le lot $\mathrm{T}$. Les performances à l'abattage des deux groupes d'animaux qui avaient pâturé ont été moins favorables que celles des taurillons qui ont été engraissés en stabulation.

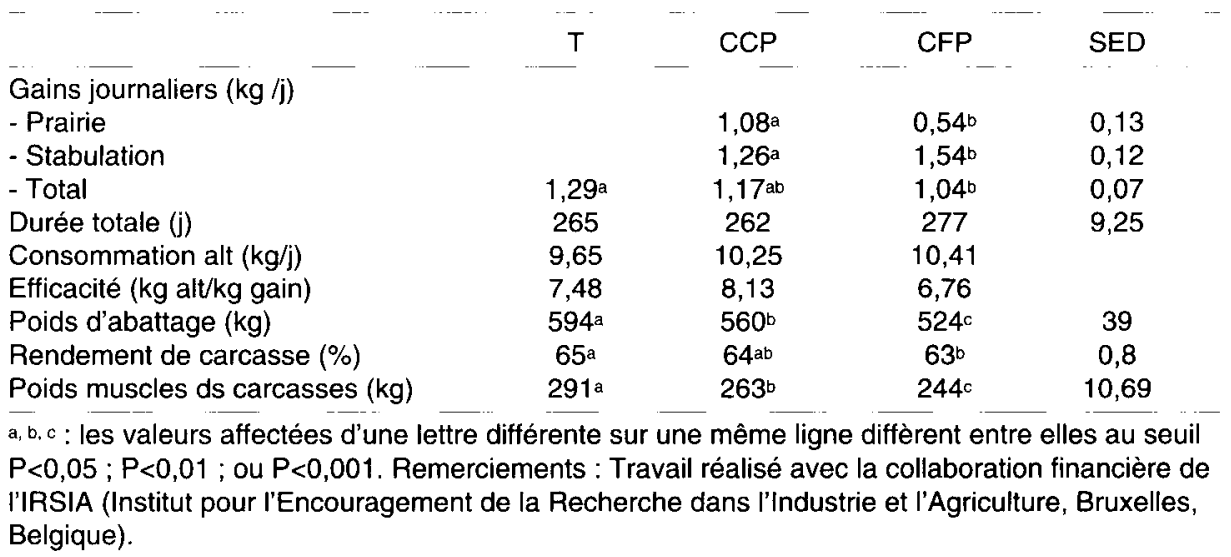

